\title{
Validity And Cost/Benefit Analysis of A Rating System Used For Promotion
}

\author{
Dr. Steven D. Norton, Management, Indiana University at South Bend \\ Dr. Joseph L. Balloun, Management, Louisiana Tech University \\ Dr. E. James Dunne, Management Information Systems \& Decision Science, University of Dayton \\ Mr. H. Edward Thornton, U.S. Fidelity and Guaranty Company, Baltimore
}

\begin{abstract}
This paper begins with a discussion of the issues involved in the validity of a rating system and its value to the organization, using the terminology introduced by Landy and Farr (1980). We then describe a large project in which a rating system was developed and used as part of the promotion process for an complex, high technology organization with several thousand employees. After describing evidence for the validity of the rating system, we provide a cost benefit analysis. We conclude with a description of the decline of the rating system.
\end{abstract}

\section{Introduction}

There are two issues in determining whether or not a rating system will achieve an acceptable outcome; validity and organizational benefit. A system having validity for a particular purpose will yield an accurate measure of performance which is important to that purpose. Validity requires both careful construction of the system and a high degree of acceptance, which can be maximized by user participation in the development process, good training, and support from top management. However, even a rating system that has demonstrable construct validity (including robustness under operational conditions), is cost effective only if the gain in organizational performance is greater than the developmental and operational costs of the system.

The cost of introducing a new rating process is due to Scale Development, Training Development and Rating Training. If an existing rating process is being replaced, there might be additional costs due to the time spent in the Rating Process and related personnel management procedures.

Landy and Farr's (1980) Process model of performance rating (shown in Figure 1) can be used to discuss both validity and cost-benefit issues. The components of the model are discussed in detail in Landy and Farr's landmark article. In their model, Scale Development refers to the development of the Rating Instrument. We have divided this process into two aspects, Instrument Construction and Scale Construction, because each aspect involves different processes and different types of evidence for the validity of the resulting Rating Instrument. The distinction is derived from that between nomological and trait evidence for construct validity (Campbell, 1960). Instrument Construction issues include the domain of the rating instrument, the number of scales necessary to cover the domain, and the method for combining scores on individual scales to determine the overall rating (Performance Description) for a particular purpose (Personnel Action). Scale construction issues include the format of the scales and the number of rating steps. We have also added Training Development (development of training material and methodology) and Rater Training to the original model. They will be discussed below.

The validity of a rating system includes all the evidence showing that it does measure what it is designed to measure. Unfortunately, the numerous issues intervening between the ratees' behavior and the recorded rating make the legal definition of a valid rating systems even more problematic than that of a valid paper-and-pencil tests. Classic validity theory and The Uniform Guidelines on Employee Selection Procedures (U.S.E.E.O.C.C.) consider three types of evidence for validity; empirical, content, and construct. Empirical validity is not usually applicable to performance ratings and content validity, as described in the Uniform Guidelines, is applicable to a narrow range of situations.(Guion, 1978; Guion, 1980; Tenopyr, 1977) (A section below discusses content 


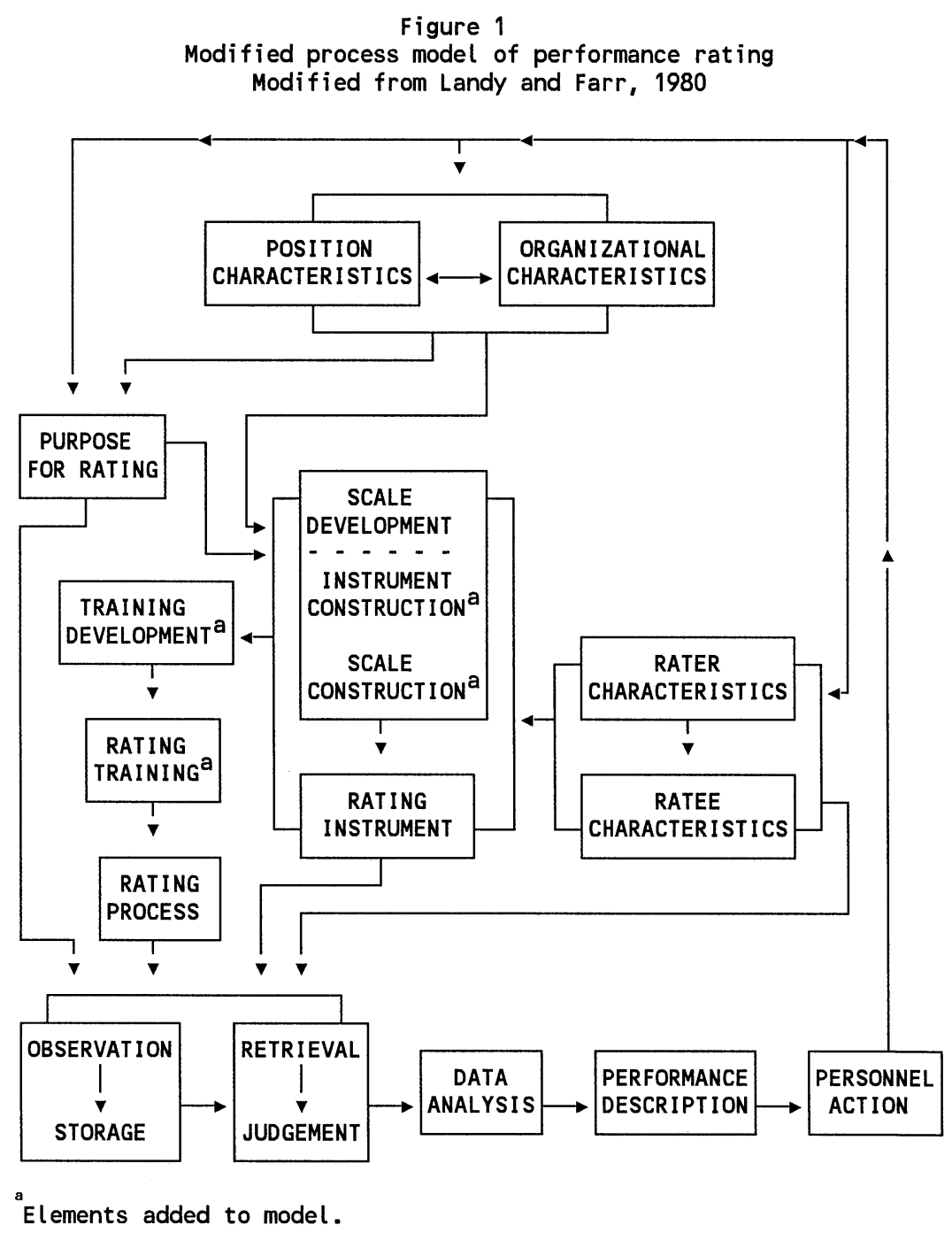

validity as a component of construct validity) We are adopting the position that there is only one kind of validity, construct validity, evidence that a measure of a psychological construct predicts a type of performance that should be associated with that construct. See Cronbach and Meehl, 1955, Cronbach et al., 1972, Guion, 1978, 1980, Kavanagh, 1971, and Tenopyr, 1977 for a discussion of this position and of content validity as a component of construct validity.

The construct validity of rating systems involves both developmental and operational issues. Empirical evidence, gathered during Scale Development under experimentally controlled conditions, should support the construct validity of the Rating Instrument. Construct validity which has been empirically demonstrated in the developmental stage should be maintained when the system is in operational conditions. This distinction between developmental and operational validity has been made in the context of traditional testing (Brown, 1979), but it is even more important with ratings.
Landy and Farr (1980) note that "since most of the published research was done in the research purpose context, too little information is currently available to draw firm conclusions about impact of purpose for ratings." The line managers who worked on the rating system discussed here felt that supervisors were extremely reluctant to rate subordinates below the middle of a rating scale, no matter what labels are placed on the rating intervals. We suggest extreme caution in utilizing research on scale characteristics such as inter-rater reliability carried out with college students to judge the characteristics of rating scales in actual use.

\section{Developmental Evidence for Construct Validity}

\section{Content Issues}

The rating form should be designed by consensus of subject matter experts to maximize its content validity, the extent to which it is representative of job content. One set of subject matter experts should propose a list of 
performance dimensions and a second set should review the list.

Each rating scale in the rating form should be designed to differentiate among levels of the construct in the ratee population. The top step of the scale should describe an unusually effective employee and the bottom step of the scale should describe the least effective employee who would avoid being demoted or fired.

\section{Process Data}

The content validity of a rating form should be established when the form is being developed. After the form has been completed, empirical evidence for the construct validity of the rating form itself and the rating processes should be gathered under carefully controlled experimental conditions, using written case studies whose realism has been established by previous reviewers. It should be established that the raters use the correct information in the case (e.g. the relevant critical incidents) to form their judgments about the ratee's performance on each rating scale.

Interrater reliability is the key issue in rating scale reliability. A good test of the reliability of the judgement process is whether raters agree on the pattern of strengths and weaknesses as they rate several diverse cases.

\section{Normative Data}

Normative data on the means, standard deviations and intercorrelations of the scales for actual employees, but in a research context (not used for actual decisions), is essential for evaluating the construct validity of the rating system under both experimental and operational conditions.

\section{Robustness of Ratings}

The "robustness" $(\mathrm{R})$ of a rating system is the extent to which the empirical properties of the developmental ratings, ratings obtained in a research context during development, are maintained in an administrative context. The robustness of a rating system with respect to the overall mean of all of the subscales can be defined as one minus eta, or the ratio of the sum of squares within the experimental or operational conditions to the total sum of squares (within and between the operational and experimental conditions). (See Equation 1 , below.) $\underline{\mathrm{R}}$ can vary between zero and one, and to the degree that $\underline{R}$ approaches one, the rating system is robust to operational conditions.

\section{The High Technology Organization's Experience}

The authors had the opportunity to observe the development and implementation of a rating system for promotability (Balloun, Dunne, Norton, and Konstantinovich, 1987). For reasons which will become evident, no information is given about the organization, beyond the fact that it is a complex high technology organization with two major divisions: (a) a set of "laboratories" which engage in applied research and advanced development, and (b) an organization of program offices and support groups which manage system engineering development efforts.

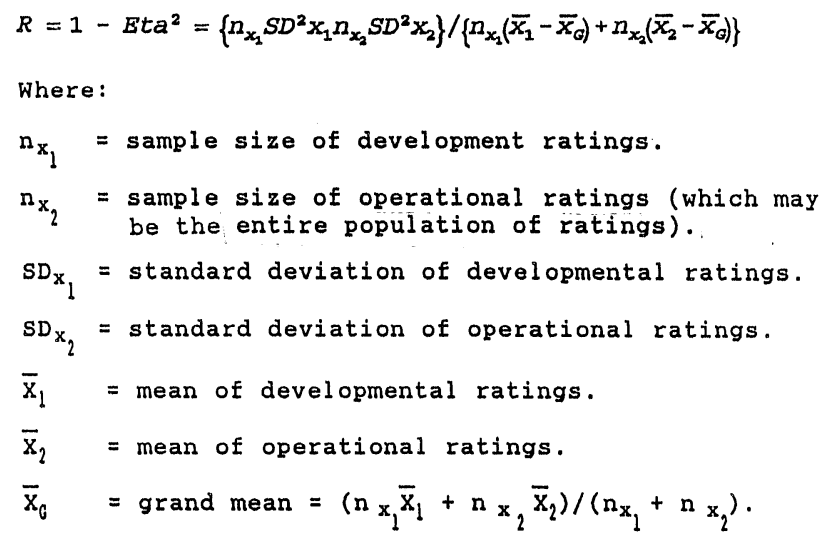

The previous rating forms had been developed by the organization's central personnel office. Depending on their job series, employees were rated on a number of graphic rating scales. The weighing of the scales to screen candidates for a particular position was determined by a personnel specialist, based on information provided by the supervisor. Both the old and the new rating forms contained seven point scales.

\section{Development of Rating Forms}

The ratings used in the previous promotion rating system for scientists and engineers had become so inflated that they no longer differentiated among candidates for promotion. In the summer of year 1 , a project team was assembled at the request of the head of the organization to revise the promotion rating system, beginning with the Form A for scientists and engineers. The content of the new rating form was defined by consensus of a group of 63 experienced supervisors of scientists and engineers.

In its first implementation, the Form $\mathrm{A}$ did reduce rating inflation. Early in year 2, the head of the organization directed the project team to revise and expand the new scientist and engineer form to cover the remaining employees. The scientist and engineer rating scales were revised to become generally applicable to all professional employees, including lawyers, physicians, and accountants. The Form A scales are listed in Table 1 and consisted of seven points, with the top, middle and bottom anchored by carefully written verbal descriptions. 
The technician or subprofessional form (Form B), developed by a small team, contained the same scales as the professional form, with the definitions and scale steps rewritten to reflect the nature of subprofessional or technician jobs. In year 2, a clerical and secretarial task force was convened to create Form $\mathrm{C}$ for secretarial and clerical jobs. After the entire task force arrived at initial scale definitions, a smaller group met to write scale steps. Form $\mathrm{C}$ contained the rating scales listed in Table 1. The final versions of Forms A, B, and C are available from the first author. See Table 1 for Normative Data on Forms A and C collected in a research context.

A second major source of developmental construct validity evidence was gathered as a part of the training program. Training cases were developed which describe one year's experience in the life of an hypothetical employee. Panels of highly experienced supervisors developed "correct" scale ratings for these training cases through intensive discussions. Before discussion, the mean interrater reliability for the scales ranged from 0.58 to 0.88 and the interrater reliability of the mean of the 10 scales (omitting Decision Making, not used for all cases) was 0.96 .

In addition to the panel data, data are available for 252 raters who rated a case in supervisory training sessions.
The interrater reliability of the mean of the 11 scales for these supervisors was 0.73 . Furthermore, training case data show that trainees appropriately discriminated among patterns of strengths and weaknesses in the different cases.

Different sources of reliability data indicate that there was adequate interrater reliability $(.70$ or more for the mean of the 11 scales) under experimental conditions. It should be noted that the cases were written to produce good discussions about complex and ambiguous scientist and engineer positions, rather than to maximize interrater reliability.

\section{Evidence for Construct Validity}

Kavanaugh (1971) suggests that multitrait-multi method analysis provides the only sufficient evidence for the relevance (in terms of construct validity) for rating stimuli. Such an analysis was attempted in the current research. Ratings were collected from ratees, their own supervisor, another supervisor familiar with their work, and a co-worker. Despite a carefully planned research methodology, the mechanics of collecting such ratings while ensuring anonymity lead to so much missing or ambiguous data that the results of the study were not usable.

TABLE 1

Research Context Normative Data for Form A and Form C

\begin{tabular}{|c|c|c|c|c|c|}
\hline Rating Scale & $\mathrm{N}$ & Mean & SD & Loading $^{8}$ & $\overline{I^{2} R^{b}}$ \\
\hline \begin{tabular}{ll} 
& \multicolumn{1}{c}{ FORM A } \\
1. & Self Management \\
2. & Work Administration \\
3. & Problem Analysis \\
4. & Decision Making \\
5. & Speaking Ability \\
6. & Writing Ability \\
7. & Working Relationships \\
8. & Work Leadership \\
9. & Personnel Management \\
10. & Perf. under Pressure \\
11. & Work Output
\end{tabular} & $\begin{array}{r}176 \\
127 \\
193 \\
179 \\
228 \\
194 \\
194 \\
125 \\
65 \\
192 \\
192\end{array}$ & $\begin{array}{l}5.45 \\
5.31 \\
5.50 \\
5.31 \\
5.09 \\
5.17 \\
5.51 \\
5.31 \\
5.31 \\
5.42 \\
5.49\end{array}$ & $\begin{array}{l}1.18 \\
1.21 \\
1.01 \\
1.03 \\
1.09 \\
1.03 \\
1.20 \\
1.29 \\
1.55 \\
1.14 \\
1.21\end{array}$ & $\begin{array}{l}.77 \\
.77 \\
.77 \\
.86 \\
.54 \\
.51 \\
.65 \\
.84 \\
.71 \\
.80 \\
.80\end{array}$ & $\begin{array}{l}.69 \\
.84 \\
.71 \\
-. c \\
.65 \\
.86 \\
.88 \\
.81 \\
.58 \\
.76 \\
.78\end{array}$ \\
\hline \begin{tabular}{ll} 
& \multicolumn{1}{c}{ Form $C^{d}$} \\
1. & Self Management \\
2. & Work Administration \\
3. & Personal Asst. Activ. \\
4. & Information Processing \\
5. & Communication \\
6. & Working Relationships \\
7. & Perf. under Pressure \\
8. & Work Output
\end{tabular} & $\begin{array}{l}30 \\
16 \\
12 \\
11 \\
29 \\
30 \\
30 \\
30\end{array}$ & $\begin{array}{l}5.63 \\
5.74 \\
5.50 \\
5.10 \\
5.40 \\
5.79 \\
5.45 \\
5.69\end{array}$ & $\begin{array}{l}1.38 \\
1.07 \\
1.08 \\
1.47 \\
1.12 \\
1.28 \\
1.53 \\
1.45\end{array}$ & & \\
\hline
\end{tabular}

\footnotetext{
${ }^{a}$ I terated first centroid factor loadings.

${ }^{\mathrm{b}}$ Interrater reliability

${ }^{\circ}$ Not reported because of problems in data collection.

${ }^{\mathrm{d}}$ Factor analysis and interrater reliability not available because of small sample sizes.
}

NOTE: The mean score and SD of the Rating Scales are 5.35 and 1.18 for Form $A$ and 5.54 and 1.30 for Form C. The SD of the mean scale score over all ratees is .89 or Form A and 1.00 for Form C. The average intercorrelations are .53 for both forms. 
Kavanagh also suggests that inter-rater reliability and consistency over time are necessary but not sufficient and that validation against other criteria may aid understanding. Enough data was available to establish inter-rater reliability, but there were no criteria against which to attempt empirical validation. It would have been futile to study the consistency of the ratings over time because of changes in management policies. Top management attempted to control the rating distribution and supervisors responded by giving high ratings primarily to employees who were likely to be considered for promotion.

Management's motivation for the development of a new rating system was the fact that employees had successfully grieved against the old rating system. The major impediments to establishing the construct validity of the new rating system were 1) management's fear of collecting data that could be used by employees in filing new grievances, and 2) suspicion (which was not entirely unwarranted) on the part of employees and supervisors, that the new system would be misused. The project staff was dealing with scientists and engineers who understood the logic of the research methodology and how it had been compromised by management actions. Another barrier to establishing system validity was the fact that the new system developed primarily for a set of complex, ambiguous jobs and the Uniform Guidelines offer little guidance on promotion decisions in general and promotion decisions for complex, ambiguous jobs in particular. They seem to favor content validity and lead to vastly oversimplified measures.(Day et al., 1981).
The developmental evidence for the construct validity of the promotion appraisal system can be summarized as follows:

1) Subject matter experts were in agreement on the content of the rating scales, and many supervisor commented favorably on the scale content during training and when the system was in use.

2) Content validity was successfully designed into the forms. The hypothesized unimodal scale distributions were achieved, and normative scale data were created.

3) When case studies were rating during training, raters achieved acceptable levels of interrater reliability, and they were able to appropriately differentiate among scales, among ratees, and among ratees' patterns of strengths and weaknesses.

4) The ratings were robust in the first use of the rating system, as discussed below.

\section{Operational Data}

One of the important aspects of the validity of a rating system is that it be robust, that the empirical properties of the ratings obtained under research conditions be maintained under administrative conditions. In order to be useful, a rating system must produce a distribution of ratings which is appropriate for the administrative purpose it is intended to serve. When a system is used to identify a small number of employees to be considered

Table 2

Times Series Data on Robustness of Overall Mean

(over all scales and ratees) for Three Groups.

\begin{tabular}{|c|c|c|c|c|c|c|c|c|}
\hline Group & Year & $\mathrm{N}$ & Mean & Median & Mode & SD & $R^{a}$ & $t^{6}$ \\
\hline Engineering & $\begin{array}{l}-2^{c} \\
-1^{c} \\
1 \\
2 \\
3 \\
4\end{array}$ & $\begin{array}{c}938 \\
938 \\
938 \\
1002 \\
1002 \\
989\end{array}$ & $\begin{array}{l}6.3 \\
6.2 \\
5.7 \\
6.1 \\
6.3 \\
6.6\end{array}$ & $\begin{array}{l}6.3 \\
6.1 \\
5.9 \\
6.2 \\
6.6 \\
6.9\end{array}$ & $\begin{array}{l}6 \\
6 \\
6 \\
6 \\
6 \\
7\end{array}$ & $\begin{array}{l}.54 \\
.58 \\
.76 \\
.61 \\
.54 \\
.43\end{array}$ & $\begin{array}{l}.76 \\
.81 \\
.98 \\
.86 \\
.77 \\
.59\end{array}$ & $\begin{array}{c}13.91^{* *} \\
12.45^{* *} \\
5.13^{* *} \\
10.98^{* *} \\
13.91^{* *} \\
18.31^{* *}\end{array}$ \\
\hline Labs & $\begin{array}{l}2 \\
3 \\
4\end{array}$ & $\begin{array}{l}1749 \\
1800 \\
1753\end{array}$ & $\begin{array}{l}5.8 \\
6.0 \\
6.2\end{array}$ & $\begin{array}{l}6.1 \\
6.2 \\
6.4\end{array}$ & $\begin{array}{l}6 \\
6 \\
7\end{array}$ & $\begin{array}{l}.72 \\
.65 \\
.58\end{array}$ & $\begin{array}{l}.97 \\
.93 \\
.87\end{array}$ & $\begin{array}{r}6.59 * * \\
9.52 * * \\
12.45 * *\end{array}$ \\
\hline Secs \& Clerks & $\begin{array}{l}2 \\
3 \\
4\end{array}$ & $\begin{array}{l}634 \\
896 \\
896\end{array}$ & $\begin{array}{l}5.5 \\
6.3 \\
6.5\end{array}$ & $\begin{array}{l}6.3 \\
6.7 \\
6.9\end{array}$ & $\begin{array}{l}7 \\
7 \\
7\end{array}$ & $\begin{array}{l}.83 \\
.54 \\
.47\end{array}$ & $\begin{array}{r}1.00 \\
.96 \\
.91\end{array}$ & $\begin{array}{r}\text { ns } \\
13.92^{* *} \\
16.85 * *\end{array}$ \\
\hline
\end{tabular}

**p<.01, one tailed.

${ }^{a}$ As robustness ( $R$ ) approaches 1.0 , the operational mean rating over all ratees and scales is closer to the developmental mean. As $R$ approaches 0 , the operational mean becomes more deviant. The developmental means were 5.35 for Form A, Engineering and Labs, and 5.54 for Form C, the Secretary/Cler. group.

${ }^{b}$ This is a one-tailed $t$ test of whether the operational mean is greater than the developmental mean.

'Data for old rating system. 
for promotion, the shape of the upper tail is more important than the mean of the ratings. Unfortunately, the concept of robustness has only been operationalized with respect to the mean (Boudreau, 1983).

The promotion appraisal system was partially implemented in the year 1 and used through year 4. Time series data for Forms A and C (in Table 2) show that, compared to the previous system, there was a substantial reduction in leniency for the first implementation of the new rating system. The robustness for Form A the first year is 0.98 , although the operational mean was significantly higher than the research context (developmental) mean during the first year of implementation. The Form $C$ robustness was 1.00 the first year, and the operational mean was not significantly higher than the research context mean. After the first year robustness declined. This decline of robustness is more apparent in the median or mode of the operational distributions than in the mean. In the second and subsequent rating cycles, the degree of leniency for clerical (Form C) employees was virtually the same as for the previous system and the leniency of the professional (Form A) employees also increased.

\section{Cost Benefit Analysis}

As Boudreau (1984) has pointed out, estimates of the financial payoffs of personnel progress need not be highly precise. Break-even analyses can use estimates of lower or upper boundaries of decision parameters to facilitate program decisions. Such boundary estimates are be easier to obtain than point estimates and adequate for many decision-making purposes. We have applied Boudreau's methodology to assessing the financial payoff of the ratings system due to improved promotion decisions. The formula and parameters used are available from the second author.

\section{Cost-Benefit Results}

Table 3 shows a cost-benefit analysis of the new rating system from years 1 to 4 for professional employees rated on Form A. Considering only the variable costs, the estimated annual dollar gains over the prior rating system for the promotions made in years 1 to 4 were respectively $\$ 444,309, \$ 2,805,860, \$ \$ 3,454,762$, and $\$ 3,357,836$. Therefore, the profit (before fixed costs) was the sum of the annual dollar gains or $\$ 10,062,767$. As noted above the fixed costs for developing and implementing the new system was approximately $\$ 172,750$. Therefore, the overall benefits for this particular system exceeded the overall costs by about ten million dollars. Even given the uncertainties of the estimates it is likely that overall system benefits were much greater than overall system costs.

\section{Conclusions and Recommendations}

\section{Validity}

The decline in Robustness discussed above, survey data not discussed in this paper, and anecdotal evidence

Table 3

Example of Calculation of Benefits for Old and New Rating systems for Professional (Form A) Employees

\begin{tabular}{|c|c|c|c|c|c|c|c|}
\hline $\begin{array}{l}\text { Rating } \\
\text { system }\end{array}$ & Year & $\begin{array}{c}N \text { of } \\
\text { jobs } \\
\text { filled }\end{array}$ & $\begin{array}{l}\text { Corrected } \\
\text { val idity }\end{array}$ & $\begin{array}{l}\text { \$ Profit } \\
\text { over } \\
\text { zero } \\
\text { validity }\end{array}$ & $\begin{array}{l}\text { \$ Profit } \\
\text { over } \\
\text { old } \\
\text { system }\end{array}$ & $\begin{array}{l}\text { \$ Profit } \\
\text { under } \\
\text { robust } \\
\text { system }^{d}\end{array}$ & $\begin{array}{l}\text { \$ Cost of } \\
\text { leniency }\end{array}$ \\
\hline $\begin{array}{l}\text { old } \\
\text { old } \\
\text { old }\end{array}$ & $\begin{array}{l}-2 \\
-1 \\
1 a^{f}\end{array}$ & $\begin{array}{l}290 \\
325 \\
284\end{array}$ & $\begin{array}{l}.155 \\
.166 \\
.132\end{array}$ & $\begin{array}{l}3,991,974 \\
4,800,317 \\
3,312,724\end{array}$ & $\begin{array}{l}\text { N/A } \\
\text { N/A } \\
\text { N/A }\end{array}$ & $\begin{array}{l}6,736,351 \\
7,549,359 \\
6,596,979\end{array}$ & $\begin{array}{l}2,774,377 \\
2,749,042 \\
3,284,255\end{array}$ \\
\hline $\begin{array}{l}\text { SUM FOR NEW } \\
\text { FIXED COSTS } \\
\text { OVERALL GAIN }\end{array}$ & $\begin{array}{l}\text { YEAR } \\
\text { IN P }\end{array}$ & YEAR 4 & & $21,109,622$ & $\begin{array}{r}10,062,767 \\
172,750 \\
\$ 9,890,017\end{array}$ & $4,382,900$ & $9,182,427$ \\
\hline
\end{tabular}

${ }^{a}$ Validity is corrected for restriction of range.

brofits due to productivity of promoted employees selected with rating system in use, compared those who would have been selected by a rating system of zero validity.

'Utility, or profits due to productivity of employees actually selected with new rating system compared to the employees who would have been selected with the old rating system.

dProfits due to productivity which would have occurred with a (hypothetical) robust rating system compared to a rating system of zero validity.

Loss in profits due to productivity under rating system actually used compared to a robust system.

fold rating system used in all units during years -2 and -1 , and used in all units except engineering in year 1. New rating system used in engineering in year 1 and in all units in years 2-4.

${ }^{g}$ For years $1 a$ and $1 b$, the number of jobs is that filled using each system. 
indicate that construct validity declined after the first operational cycle. The major causes of the decline include (a) mistrust among major organizational subunits, (b) positive reinforcement of supervisors for inflationary rating behavior, and (c) diffused and delayed responsibility for controlling inflation. When the organization's head left, his replacement was indifferent to the new rating system and attempted to control inflation by imposing quotas. This change destroyed the construct validity of the appraisal system by forcing raters to decide on an overall rating, and then select individual ratings summing to that overall rating.

\section{Benefits}

The net benefit of this carefully developed rating system appear to be about ten million dollars. Less quantifiable benefits from appraisal systems should not be ignored. Survey results indicated that many supervisors found the rating scales highly useful for thinking about and discussing current job performance and career development needs with their subordinates. Most ratees shared this perception of the content of the scales. Less benignly, when inflation destroyed the construct validity of the rating system, many managers and employees perceived the result as another confirmation of the poor performance of the personnel department.

An earlier version of this article appeared in the Proceed ings of the 1991 Meeting of the Midwest Management Society, Chicago, April, 1991.

\section{References}

1. Balloun, J. L., Dunne, J. E., Thornton, H. E., Norton, S. D., and Konstantinovich, B., Implementing a Promotion Appraisal System: The Case of the High Technology Company, International Case Clearing House, Lord Publishing, Dover, Ma. 1987.

2. Balloun, J.L., Norton, S.D., and Konstantinovich, B., "A Critical Review of Issues in Promotion Appraisal Systems for High Technology Organizations," JSAS Catalog of Selected Documents in Psychology, Vol, 8, Manuscript No. 1786, 1979.

3. Boudreau, J.W., "Economic Considerations in Estimating the Utility of Human Resource Productivity Programs." Personnel Psychology, Vol. 36, pp. 551-576, 1984

4. Brown, S.H., "Validity Distortions Associated with a Test in Use." Journal of Applied Psychology, Vol. 64, No. 4, pp. 460-462, 1979.

5. Campbell, D.T., "Recommendations for APA Test Standards Regarding Construct, Trait, or Discriminant Validity." The American Psychologist, Vol. 15, No. 8, pp. 546-553, 1960.

6. Campbell, J.P., Dunnette, M.D., Arvey, R.D. \& Hellervik, L.V., "The Development and Evaluation of Behaviorally Anchored Rating Scales. Journal of Applied Psychology, Vol. 57, No. 1, pp. 15-22, 1973.

7. Cronbach L. J. and Meehl, P.E. "Construct Validity in Psychological Tests." Psychological Bulletin, Vol. 52, pp. 281-302, 1955.

8. Day, V.G., Erwin, F., and Koral, A.M. (Eds.), A Professional and Legal Analysis of the Uniform Guidelines on Employee Selection Procedures. Berea, Ohio: American Society for
Personnel Administration, 1981

9. Ferguson, G. A., Statistical Analysis in Psychology \& Education. (4th ed.). New York: McGraw-Hill, 1976.

10. Gomez-Mejia, L.K., Page, R.C., and Tornow, W.W., "Improving the Effectiveness of Performance Appraisal." Personnel Administrator. Vol. 30, NO. 1, pp. 74-81, 1985.

11. Guion, R.M., "'Content Validity' in Moderation," Personnel Psychology. Vol. 31, p. 205213, 1978.

12. Guion, R.M., "On Trinitarian Doctrines of Validity." Professional Psychology. Vol. 1: 385-398, 1980.

13. Kavanagh, M. J., "The Content Issue in Performance Appraisal: A Review," Personnel Psychology, Vol. 24, pp. 653-668, 1971

14. Kavanagh, M.J., MacKinney, A.C. \& Wolins, L., "Issues in Managerial Performance: Multitrait-multimethod Analyses of Ratings." Psychological Bulletin, Vol. 75, No. 1, 34-49, 1971.

15. Landy, F.J. \& Farr, J.L., "Performance Rating," Psychological Bulletin, Vol. 87, No. 1, pp. 72-107, 1980.

16. Landy, F.J., Farr, J.L. \& Jacobs, R.R., "Utility Concepts in Performance Measurement." Organizational Behavior and Human Performance, Vol. 30, pp. 15-40, 1982.

17. Landy, F.J. \& Barnes, J.B., "Scaling Behavioral Anchors," Applied Psychological Measurement, Vol. 3, No. 2, 193-200, 1979.

18. Landy, F.J., Barnes-Farrell, J.B., \& Cleveland, J.N., "Perceived Fairness and Accuracy of Performance Evaluation: A Follow-up," Journal of Applied Psychology, Vol. 65, No. 3, pp. 355-356, 1980.

19. Landy, F.J., Vance, R.J., Barnes-Farrell, J.B. \& Steele, J.W., "Statistical Control of Halo Error in Performance Ratings," Journal of Applied Psychology, Vol. 65, No. 5, pp. 501-506, 1980.

20. Lawshe, C.H., "A Quantitative Approach to Content Validity," Personnel Psychology, Vol. 28, pp. 563-575, 1975.

21. Schmidt, F.L. and Hunter, J.E., "Individual Differences in Productivity: An Empirical Test of Estimates Derived from Studies of Selection Procedure Utility," Journal of Applied Psychology. Vol. 68, No. 3, pp. 407-414, 1983.

22. Tenopyr, M.L., "Content-construct Confusion." Personnel Psychology. Vol. 30, pp. 47-54, 1977.

23 U.S. Equal Employment Opportunity Coordinating Council, "Uniform Guidelines on Employee Selection Procedures," Federal Register. Vol. 43, No. 166, 1978. 